\title{
CANNABINOID AND CHOLINERGIC SYSTEMS INTERACT DURING PERFORMANCE OF A SHORT-TERM MEMORY TASK IN THE RAT
}

\author{
Anushka V. Goonawardena ${ }^{1}$, Lianne Robinson ${ }^{2}$, Robert E. Hampson ${ }^{1,2}$, and Gernot \\ Riedel ${ }^{1,2,3}$ \\ 1 Department of Physiology and Pharmacology, Wake Forest University School of Medicine, \\ Winston-Salem, North Carolina 27157-1083, USA \\ 2 School of Medicine and Life Sciences, University of Aberdeen, Aberdeen, Scotland AB25 2ZD, \\ United Kingdom
}

\section{Abstract}

It is now well established that cannabinoid agonists such as D9-tetrahydrocannabinol (THC), anandamide, and WIN 55,212-2 (WIN-2) produce potent and specific deficits in working memory (WM)/short-term memory (STM) tasks in rodents. Although mediated through activation of CB1 receptors located in memory-related brain regions such as the hippocampus and prefrontal cortex, these may, in part, be due to a reduction in acetylcholine release (i.e., cholinergic hypofunction). To determine the interaction between cannabinoid and cholinergic systems, we exposed rats treated with WIN-2 or cholinergic drugs to a hippocampal-dependent delayed nonmatch to sample (DNMS) task to study STM, and recorded hippocampal single-unit activity in vivo. WIN-2 induced significant deficits in DNMS performance and reduced the average firing and bursting rates of hippocampal principal cells through a CB1 receptor-mediated mechanism. Rivastigmine, an acetylcholinesterase inhibitor, reversed these STM deficits and normalized hippocampal discharge rates. Effects were specific to $1 \mathrm{mg} / \mathrm{kg}$ WIN-2 as rivastigmine failed to reverse the behavioral and physiological deficits that were observed in the presence of MK-801, an NMDA receptor antagonist. This supports the notion that cannabinoid-modulated cholinergic activity is a mechanism underlying the performance deficits in DNMS. Whether deficits are due to reduced nicotinic or muscarinic receptor activation, or both, awaits further analysis.

\section{Introduction}

Administration of both synthetic and phytocannabinoids, including D9tetrahydrocannabinol (D9-THC), WIN 55,212-2 (WIN-2), and CP 55,940, impair working memory (WM) and short-term memory (STM) through a CB1 receptor-mediated mechanism in rats (Lichtman et al. 1995; Lichtman and Martin 1996; Hampson and Deadwyler 1998, 1999, 2000; Braida and Sala 2000; Egashira et al. 2002). This suggestive evidence for endocannabinoid involvement in memory formation was confirmed by Terranova and coworkers (1996), who demonstrated that the CB1 receptor antagonist rimonabant facilitated short-term olfactory memory, and this was partially reversed by the muscarinic receptor antagonist scopolamine. This suggests an interaction between cannabinoid and cholinergic systems such that endocannabinoid tone suppresses cholinergic transmission. Consequently, rats pretreated with eptastigmine, a second-generation cholinesterase inhibitor remained unaffected by the full CB1 receptor agonist CP 55,940

\footnotetext{
${ }^{3}$ Corresponding author. g.riedel@abdn.ac.uk; fax 44-1224-555741. .
} 
when tested in an eight arm radial maze (Braida and Sala 2000). And more recent evidence from Mishima and coworkers (2002) suggests that a block of cholinesterase with physostigmine and tetrahydroaminoacridine protects against WM impairments induced by D9-THC. These findings further support a potential role of the cholinergic system in cannabinoid-induced memory impairments.

The exact mechanisms for this interaction still remain elusive, although cholinergic projection neurons from medial septum to hippocampus are likely to play an important role (Harkany et al. 2003, 2005; Fitz et al. 2008). However, the neuromodulatory action of pharmacologically active cannabinoids on septo-hippocampal cholinergic activity in vivo remains unexplored. Within the hippocampus, cannabinoids presynaptically inhibit the release of acetylcholine, possibly through the activation of CB1 receptors located on cholinergic nerve terminals given that these effects were blocked by rimonabant (Gifford and Ashby 1996; Gifford et al. 1997a, 2000; Kathmann et al. 2001a). Direct in vivo microdialysis studies in awake rats also showed cannabinoid-induced decreases in acetylcholine release in the hippocampus through a CB1 receptor-mediated mechanism (Gessa et al. 1997; Carta et al. 1998). High doses of rimonabant alone increase the amount of acetylcholine release in the hippocampus (Gessa et al. 1997, 1998) either by blocking the tonic inhibitory influence of endocannabinoids and/or through its inverse agonism at CB1 receptors. Such actions are in agreement with a $100 \%$ greater increase in electrically evoked hippocampal acetylcholine release in CB12/2 mice (Kathmann et al. 2001b).

In contrast, low doses of $\Delta^{9}$-THC $(0.01-0.15 \mathrm{mg} / \mathrm{kg})$, WIN-2 (0.01-0.5 mg/kg), and HU-210 $(0.001-0.004 \mathrm{mg} / \mathrm{kg}$ ) have been shown to enhance acetylcholine release (Acquas et al. 2000, 2001), indicating that cannabinoid modulation of acetylcholine release in the hippocampus is "biphasic." This has been further supported by the work carried out by Tzavara and coworkers (2003), who demonstrated that low $(0.5 \mathrm{mg} / \mathrm{kg}$, intraperitoneally [i.p.]) and high $(5 \mathrm{mg} / \mathrm{kg}$, i.p.) doses of WIN-2 induce transient stimulation and prolonged inhibition of hippocampal acetylcholine efflux, respectively. This demonstrates that the dose of cannabinoids plays a key role in determining how much acetylcholine is released in the hippocampus.

Such an interaction is likely to play an important role during the performance of a delayed nonmatch to sample (DNMS) task but has not been explored. Hence, a comprehensive pharmacological assessment was carried out here to (1) reveal the existence of such an interaction in terms of DNMS performance and (2) assess a possible cannabinoidacetylcholine cross-talk on burst characteristics of hippocampal principal cells in CA3 and CA1.

\section{Results}

\section{Experiment 1-rivastigmine reversed scopolamine induced deficits in DNMS performance}

Prior to assessing the possible interaction between cannabinoid and cholinergic systems, it was important to establish whether the blockade of cholinergic neurotransmission by scopolamine was able to produce deficits in DNMS performance, as seen with other learning and memory tasks (Bejar et al. 1999; Wang et al. 2000). Second, we aimed to corroborate that scopolamine deficits could be reversed by co-administration of rivastigmine. Behavioral data are summarized in Figures 1 and 2 and support the hypothesis that muscarinic receptor blockade inhibits DNMS performance independent of delay and without effect on reaction times. Co-administration of rivastigmine recovered normal performance; rivastigmine alone was not detrimental. 
Consequently, overall one-way repeated-measures ANOVA on the percentage of correct responses yielded a main effect of treatment $(\mathrm{F}(3,15)=8.87, \mathrm{p}<0.01)$, and post-hoc analysis confirmed the impression of scopolamine-induced deficits that were recovered by rivastigmine (see asterisks in Fig. 2A). Interestingly, the scopolamine- induced deficit was delay-independent (Fig. 2B), and thus a two-way repeated-measures ANOVA performed using treatment and delay interval as within-subject factors failed to reveal an interaction, but there were main effects of treatment $(\mathrm{F}(3,100)=37.6, \mathrm{p}<0.001)$ and delay interval $(\mathrm{F}(5,100)=21.7, \mathrm{p}<0.001)$. This treatment effect was only due to amnesic performance in the scopolamine group $(\mathrm{F}(1,50)=69.8, \mathrm{p}<0.001)$ since no other treatment condition differed from vehicle, thereby confirming full reversal by rivastigmine $(F(1,50)=22.6, p<0.001)$ (for comparison of interval epochs between scopolamine alone and scopolamine + rivastigmine, see hashes in Fig. 2B). Finally, we obtained no drug-related differences in locomotor activity measured as mean reaction time to approach the response lever following completion of the nosepoke (Fig. 2C).

\section{Experiment 2a-rivastigmine reversed WIN-2-induced deficits in DNMS performance}

At least some of the cannabinoid-induced deficits in STM may be brought about by a selective reduction in the overall cholinergic tone. Hence, enhancing brain acetylcholine levels with rivastigmine could reverse these impairments. We therefore repeated our previous work and impaired DNMS performance by administering WIN-2. As reported (Hampson and Deadwyler 2000), WIN-2 impaired overall performance (Fig. 3A) in a delay dependent manner (Fig. 3B), and these deficits were fully reversed by rivastigmine, while scopolamine exacerbated the deficit further. This impression was confirmed statistically by a main effect of treatment $(\mathrm{F}(3,15)=28.42, \mathrm{p}<0.001)$ on overall DNMS performance and post-hoc analyses (see asterisks in Fig. 3A). Also, we obtained a treatment $\times$ delay interval interaction $(\mathrm{F}(15,100)=1.98, \mathrm{p}<0.05 ; \mathrm{Fig}$. 3B $)$ and main effects of treatment $(\mathrm{F}(3,100)=$ $30.74, \mathrm{p}<0.001)$ and delay interval $(\mathrm{F}(5,100)=12.94, \mathrm{p}<0.001)$. Both WIN-2 $(\mathrm{F}(1,50)=$ $47.4, \mathrm{p}<0.001)$ and WIN-2 + scopolamine $(\mathrm{F}(1,50)=52.1, \mathrm{p}<0.001)$ groups reliably differed from vehicle, respectively, but WIN-2 + rivastigmine did not. However, the WIN-2 + rivastigmine differed significantly from WIN-2 alone $(F(1,50)=35.37, \mathrm{p}<0.001)$ (for comparisons of individual delay epochs, see hashes in Fig. 3B). Similarly, asterisks in Fig. 3B show the comparisons between the WIN-2 and vehicle treatments for each interval epoch. As before, these deficits were not paralleled by motor impairments (data not shown).

\section{Experiment $2 \mathrm{~b}-$ WIN-2 reduced spontaneous firing and bursting of hippocampal CA3 and CA1 principal cells: Effects of rivastigmine}

Based on these behavioral results, we next explored the possibility that rivastigmine may also reverse the shunting of hippocampal bursts and discharge patterns induced by WIN-2 (Goonawardena et al. 2010).We kept both infusion routes and doses constant and isolated extracellular action potentials of 24 CA3 and CA1 principal cells ( $\mathrm{n}=6$ animals) following the sequential injection of vehicle (Pluronic F68), WIN-2, and rivastigmine and monitored spontaneous "firing rate" and short duration "burst" characteristics of continuous spike trains. Overall analyses revealed main effect of treatment for both average firing frequency $(\mathrm{F}(2,46)=8.74, \mathrm{p}<0.01)$ (Fig. 4B) and interspike interval (ISI; $\mathrm{F}(2,46)=9.45, \mathrm{p}<0.01)$ (Fig. 4 respectively.WIN-2significantly decreased average firing frequency $(t=2.69, \mathrm{p}<0.05)$ (Fig. $4 \mathrm{~A}$ )and, as a corollary, increased average ISI $(\mathrm{t}=2.35, \mathrm{p}<0.05)$ (Fig. 4B). Both alterations were reversed by rivastigmine (all $\mathrm{t}>2.49, \mathrm{p}<0.05$ ). Representative sample firing histograms and raster plots for the three drug conditions are depicted in Figure 4, C and D. In separate experiments, we also confirmed that rivastigmine alone had no effect on spontaneous firing characteristics of hippocampal cells (data not shown). In addition, an overall main effect of treatment was evident for the average number of bursts, interburst interval (IBI), ISIs in bursts, frequency in bursts, and spikes per bursts (all Fs . 4.37, Ps , 0.05). Post-hoc analysis 
confirmed that WIN-2 significantly decreased the average number of bursts $(\mathrm{t}=2.35$, $\mathrm{p}<0.05)$ (Fig. 5A), frequency in bursts $(\mathrm{t}=3.78, \mathrm{p}<0.01)$ (Fig. 5E), and spikes per burst $(\mathrm{t}=$ 2.60, $\mathrm{p}<0.05)$ (Fig. 5F), and increased average IBIs $(\mathrm{t}=3.26, \mathrm{p}<0.01)($ Fig. $5 \mathrm{C})$ and ISIs in bursts $(\mathrm{t}=2.48, \mathrm{p}<0.05)$ (Fig. 5D) compared with controls. However, burst durations were not affected by the cannabinoid. In contrast to the effects on WIN-2-induced changes in firing rate (Fig. 4A), rivastigmine failed to reverse the cannabinoid induced changes across all burst characteristics, as summarized in Figure 5.

\section{Experiment 3-WIN-2 reduced spontaneous firing and bursting of hippocampal CA3 and CA1 principal cells in a CB1 receptor-dependent manner}

We next explored whether WIN-2 acted through CB1 receptors when reducing spontaneous firing and bursting of hippocampal neurons. Consequently, 12 hippocampal CA3 and CA1 principal cells were isolated and recorded following vehicle, WIN-2, and AM-281 treatment, respectively. Significant effects of treatment were evident for both average firing frequency $(\mathrm{F}(2,22)=14.34, \mathrm{p}<0.001)$ (Fig. 6A) and ISIs $(\mathrm{F}(2,22)=14.34, \mathrm{p}<0.001)$ (Fig. 6B). As already seen before (Experiment $2 \mathrm{~b}$ ), the firing rates were diminished $(\mathrm{t}=4.33, \mathrm{p}<0.01$ ) (Fig. 6A) and ISIs were prolonged $(\mathrm{t}=3.96$, $\mathrm{p}<0.05)$ (Fig. 6B) by WIN-2, and this was reversed by subsequent treatment with AM-281 (all t>3.56, p<0.01) (Fig. 6A,B), suggesting that WIN-2-induced suppression in hippocampal firing was CB1 mediated. Together with the reversal observed with rivastigmine in Experiment 2, it seems to suggest that CB1 receptors modulate cholinergic activity. However, in contrast to rivastigmine, most WIN-2induced alterations in burst firing characteristics were reversed by AM-281 (Fig. 7A,C-E, see asterisks for statistical comparisons) and are thus pharmacologically not mediated through a cholinergic mechanism. Representative discharge (rate) histograms and raster plots of a CA1 principal cell depicted in Figure 6, C and D, further illustrate this point. AM-281 alone had no influence on burst characteristics of hippocampal principle cells (data not shown).

\section{Experiment 4a-rivastigmine reversed WIN-2-induced but not MK-801-induced deficits in DNMS performance}

Although results from Experiment 2 provide evidence for a strong interaction between cannabinoid and cholinergic systems, it is somewhat difficult to draw conclusions on whether WIN-2 acted directly on cholinergic neurons or indirectly via a reduction of glutamatergic excitation; the latter would also result in STM deficits (for review, see Riedel et al. 2003). Thus, we assessed DNMS performance in the presence of both the NMDA receptor blocker MK-801 alone or MK-801 in combination with either WIN-2 or rivastigmine or WIN-2 and rivastigmine together. This yielded a main effect of treatment $(\mathrm{F}(4,20)=15.71, \mathrm{p}<0.001)$. A low dose of MK-801, which did not cause motor side effects, impaired DNMS performance $(\mathrm{t}=3.88, \mathrm{p}<0.01)$ (Fig. 8A) in a delay-independent manner (Fig. 8B) in comparison to vehicle. Post-hoc t-test with Bonferroni corrections revealed that WIN-2 further impaired performance to amnesic levels when given together with MK-801 ( $t$ $=7.67, \mathrm{p}<0.001$ ), and only the WIN-2 component (but not the MK-801 component) was reversed by rivastigmine since (1) the DNMS performance following treatment of MK-801 alone and MK-801 + rivastigmine did not significantly differ from each other $(\mathrm{t}=0.39, \mathrm{P}$. 0.05), although both treatments produced significant deficits in comparison to vehicle (MK-801 vs. vehicle: $\mathrm{t}=3.88, \mathrm{p}<0.01 ;$ MK- $801+$ rivastigmine vs. vehicle: $\mathrm{t}=3.49$, $\mathrm{p}<0.05$ ), and (2) performance following MK-801 + WIN-2 + rivastigmine did not significantly differ from MK-801 alone ( $t=1.60, \mathrm{P} .0 .05)$, although MK-801 + WIN-2 group was significantly impaired from the MK-801 group $(t=3.80, p<0.05)$. For all pairwise comparisons, see asterisks in Figure 8A. 
Factorial ANOVA performed using treatment and delay interval yielded main effects of treatment $(F(4,125)=12.71 ; p<0.001)$ and delay interval $(F(5,125)=24 ; p<0.001)$, which was subsequently confirmed as deficits in the MK-801 $(\mathrm{F}(1,50)=18.69 ; \mathrm{p}<0.01)$, MK-801+ WIN-2 $(F(1,50)=82.25 ; \mathrm{p}<0.001)$, and MK-801 + rivastigmine $(F(1,50)=13.93 ; \mathrm{p}<0.01)$ condition and reversal by rivastigmine to a performance equivalent to the MK-801 condition $(\mathrm{MK}-801+\mathrm{WIN}-2$ vs. MK-801 $[\mathrm{F}(1,50)=11.96 ; \mathrm{p}<0.01] ; \mathrm{MK}-801+\mathrm{WIN}-2+$ rivastigmine vs. MK-801 $[\mathrm{F}(1,50)=1.8 ; \mathrm{P}=0.20])$. Deficits arising from $\mathrm{MK}-801$ alone and MK-801 + WIN-2 exposure were delay independent as there was no interaction between treatment and delay intervals $(\mathrm{F}, 1)$. The pair-wise comparisons for individual delays between vehicle vs. MK- 801 and vehicle vs. MK- $801+$ WIN-2 are shown in asterisks and hashes, respectively, in Figure 8B. As in all experiments described above, there were no motor disabilities in the different drug conditions (data not shown).

\section{Experiment $4 b$-rivastigmine reversed the WIN-2-induced suppression in hippocampal principal cell firing, even in the presence of MK-801}

The same drugs and doses were administered to anaesthetized rats, and extracellular action potentials of 30 principal cells ( $\mathrm{n}=6$ animals) isolated from CA3 and CA1 were recorded following treatment with vehicle, MK-801, WIN-2, and rivastigmine, respectively. Overall analysis revealed a main effect of treatment for both firing frequency $(\mathrm{F}(3,87)=9.74$, p $<0.001$; Fig. 9A $)$ and ISI $(F(3,87)=5.48, p<0.001$; Fig. 9B $)$, respectively. MK-801 significantly reduced the average firing frequency $(t=3.70, p<0.001$; Fig. 9A) and hence increased the average ISI $(t=3.55, p<0.01$; Fig. 9B $)$ in comparison to vehicle. Subsequent WIN-2 administration reduced both parameters even further (all $\mathrm{t}>2.4, \mathrm{p}<0.05$ ), and rivastigmine fully reversed the WIN-2 component of this suppression (all $\mathrm{t}>2.2, \mathrm{p}<0.05$ vs. WIN-2), but not the MK-801 components. This is further illustrated in rate histograms and raster plots (Fig. 9C,D). All other burst parameters that were altered in the presence of MK-801 and WIN-2 (average number of bursts, frequency in bursts, spikes per burst, IBI, and ISI in bursts) were insensitive to rivastigmine treatment (all Ps , 0.05 relative to vehicle; data not shown).

\section{Discussion}

Our data provide two important findings: (1) They not only confirm cannabinoid-induced deficits in DNMS performance as shown in previous studies (Heyser et al. 1993; Hampson and Deadwyler 2000; Hampson et al. 2003) but also provide the first and compelling evidence that such STM deficits were fully reversed by the cholinesterase inhibitor rivastigmine. Specificity of the cannabinoid-cholinergic interaction was provided by the presence of MK-801, an NMDA blocker, which also impaired STM, but this deficit was not reversed by rivastigmine; (2) electrophysiological recordings from hippocampal principal cells indicate that some of the WIN-2-induced alterations are reversed by rivastigmine, and again this was specific and did not transfer to MK-801. It is therefore not unreasonable to assume that WIN-2 can activate CB1 receptors either directly on cholinergic cells or indirectly through unknown intermediate mechanisms. Clearly, reduced cholinergic activity affects firing and bursting patterns of CA3/CA1 principal neurons, consequently diminishing performance in the DNMS task.

The importance of cholinergic modulation especially for learning and memory has a long tradition (for review, see Riedel and Platt 2004). Within this framework, low doses of the muscarinic acetylcholine receptor antagonist scopolamine have been widely utilized to selectively block cognition in humans (Beatty et al. 1986; Thomas et al. 2008), monkeys (Hironaka and Ando 1996), rats (Bejar et al. 1999; Wang et al. 2000), and mice (Deiana et al. 2009), while higher doses ( $2 \mathrm{mg} / \mathrm{kg}$ ) also impaired visual acuity (Robinson and Riedel 2004). It is thus not surprising that scopolamine also prevented STM in DNMS in 
Experiment 1 and that deficits were reversed by rivastigmine. Such efficacy has been observed previously (Bejar et al. 1999; Wang et al. 2000; Deiana et al. 2009) and forms the scientific support for the clinical use of rivastigmine in Alzheimer's disease.

More interestingly, rivastigmine also reversed the STM deficit induced by WIN-2 in a global manner, improving performance at all delay intervals. This, on one hand, corroborates our published work on cannabinoid-induced STM deficits in DNMS (Heyser et al. 1993; Hampson and Deadwyler 2000; Hampson et al. 2003; Goonawardena et al. 2009), but this, on the other hand, extends it by firmly establishing a link with the cholinergic system in this task. Such a link has been proposed previously (for review, see Riedel and Platt 2004; Robinson and Riedel 2004; Riedel and Davies 2005). However, Experiments 2a and $2 b$ clearly suggest that WIN-2 not only affects cholinergic transmission since (1) WIN-2 exacerbated the scopolamine induced STM impairment and (2) rivastigmine only reversed the suppression of cell firing at rest, but not the diminished burst firing patterns. Based on these results, we assume that cannabinoids are responsible for a reduction (i.e., hypofunction) in cholinergic activity in certain memory-related brain areas, including the hippocampus, and this effect diminishes cognitive performance. Although we are the first to demonstrate efficiency for rivastigmine, Mishima and coworkers (2002) applied physostigmine and tetrahydroaminoacridine to overcome WM deficits induced by the partial cannabinoid agonist D9-THC in the eight-arm radial maze. D9-THC decreased acetylcholine release in the dorsal hippocampus, as revealed by in vivo microdialysis techniques, and this was also reversed by tetrahydroaminoacridine. Similarly, a single oral dose of eptastigmine antagonized the WM impairments induced by CP55940 (Braida and Sala 2000). Despite this behavioral and biochemical evidence in support of cannabinoidcholinergic cross-talk, physiological in vivo evidence for such an interaction is lacking. Similar to HU-210 (Robinson et al. 2007), WIN-2 also suppressed the mean firing frequency and most "burst" characteristics of hippocampal principal cells. This overall suppression of excitation may provide the neurophysiological basis for the behavioral deficits, and reversal of some of these parameters by rivastigmine supports this rationale. More specifically, it appears that normalization of overall firing frequency is the critical parameter for the recovery of behavioral function, and since rivastigmine was similarly active in both CA1 and $\mathrm{CA} 3$, we are unable to pinpoint which hippocampal subregion carries the WIN-2 effects. The fact that WIN-2 effects are mediated by CB1 receptors is evident from our coadministration of AM-281 in Experiment 3, which replicates our previous work (Hampson and Deadwyler 2000) but does not clearly distinguish between a direct or indirect effect of WIN-2 on CB1 receptors located on cholinergic cells.

In agreement with a direct action is the observation that WIN-2 (and CP 55,940) inhibited electrically evoked acetylcholine release in hippocampal slices, and this is prevented by rimonabant or AM-281 (Gifford and Ashby 1996; Gifford et al. 1997a,b). In vivo brain microdialysis studies only provide supportive evidence for cannabinoid-induced reductions in cholinergic tone (Gessa et al. 1997; Carta et al. 1998; Nava et al. 2001) but cannot distinguish whether this is a direct mechanism. Alternatively, indirect actions could utilize CB1 receptors located at glutamatergic synapses (Sullivan 1999; Katona et al. 2006; Kawamura et al. 2006; Monory et al. 2006; Takahashi and Castillo 2006), thereby reducing the excitatory drive within the hippocampus, or those receptors present at terminals of cholecystokinin (CCK)-positive GABAergic interneurons (Katona et al. 1999; Tsou et al. 1999). However, if WIN-2 were to activate CB1 receptors on presynaptic terminals of GABAergic interneurons, one would predict an overall increase in hippocampal principal cell firing and bursting. In contrast, we observed a robust reduction in firing and bursting. Hence, the observed result cannot readily be explained by a simple reduction in GABA release. As for a reduction in glutamate release, we reasoned that this would also impair plasticity at glutamatergic terminals and thus prevent the encoding of task-relevant 
information. This was probed in vivo by administering MK-801 to block NMDA receptor dependent plasticity. Both in terms of WIN-2 effects on performance in DNMS and in reduced overall firing rates, we observed a dissociation from MK-801 actions in the presence of rivastigmine; WIN-2 effects were reversed, and MK- 801 deficits remained. This is compelling evidence that blockade of synaptic plasticity at glutamatergic synapses in the hippocampus can impair STM in the DNMS task, but it is mechanistically distinct from the cannabinoid actions on the cholinergic system. Rather, data suggest a direct activation of CB1 receptors on cholinergic neurons by systemically administered WIN-2, which is overcome by inhibition of acetylcholine breakdown. From a concomitant study, we have evidence that such cannabinoid- cholinergic interactions are more widespread and can also account for long-term memory deficits induced by WIN-2 in the water maze (Robinson et al. 2010).

In conclusion, we here report that WIN-2-induced deficits in DNMS performance are due to inhibited cholinergic activation within the hippocampus of rats. This effect is most likely due to the activation of $\mathrm{CB} 1$ receptors on cholinergic cells but is not region specific as it affects both CA1 and CA3 equally. Moreover, normalization of the overall firing rate in pyramidal neurons appears to recover behavioral function in a glutamate-independent manner. It remains to be determined where exactly WIN-2 produces its effects, and experiments using local administration of WIN-2 are underway to resolve this issue.

\section{Materials and Methods}

\section{Animals}

Thirty-six adult (120-150 d) male Long-Evans rats (Harlan, 275-325 g) were used. Eighteen $(\mathrm{n}=18)$ animals were water-restricted to $83 \%$ of their ad libitum body weight and individually housed in a temperature-controlled $\left(20^{\circ} \mathrm{C}-22^{\circ} \mathrm{C}\right)$ environment with a 12 -h: 12 -h light/dark cycle with free access to food. All subjects were pretrained to the same DNMS performance criteria (90\% at 1- to 5-sec delays) prior to assessing drug effects on DNMS performance across respective experiments (Experiment 1, $\mathrm{n}=6$; Experiment 2a, $\mathrm{n}=6$; Experiment $4 \mathrm{a}, \mathrm{n}=6$ ). Water consumed during each behavioral session was recorded, and a supplemental volume was given immediately after the session followed by $20-22 \mathrm{~h}$ of water deprivation. The remaining animals $(n=18)$ were not pretrained to perform the DNMS task; instead they were surgically implanted with multi-electrode arrays for electrophysiological single unit recordings in vivo across respective experiments (Experiment $2 \mathrm{~b}, \mathrm{n}=6$; Experiment 3, $\mathrm{n}=6$; Experiment $4 \mathrm{~b}, \mathrm{n}=6$ ). All animal care and experimental procedures including water deprivation and surgery were in concordance with the National Institutes of Health (NIH), Association for Assessment and Accreditation of Laboratory Animal Care (AAALAC) regulations for care and use of experimental animals and UK Animals (Scientific Procedures) Act 1986.

\section{Drug preparation}

Scopolamine, a muscarinic acetylcholine receptor antagonist; WIN-2, a nonselective (CB1/ CB2) cannabinoid receptor agonist; MK-801, a NMDA receptor antagonist; AM-281, a CB1 receptor antagonist/inverse agonist (all purchased from Sigma); and rivastigmine, an acetylcholinesterase inhibitor (Novartis) were all dissolved in ethanol to make a $20 \mathrm{mg} / \mathrm{mL}$ stock solution. The detergent vehicle was prepared from Pluronic F68 (Sigma) also as a 20 $\mathrm{mg} / \mathrm{mL}$ solution in ethanol. Thereafter, $0.5 \mathrm{~mL}$ of each drug solution was mixed with $2.0 \mathrm{~mL}$ of detergent/ethanol, to which $2.0 \mathrm{~mL}$ of saline $(0.9 \%)$ was added slowly. The solution was stirred rapidly and placed under a steady stream of nitrogen gas to evaporate the ethanol $(\approx 10 \mathrm{~min})$. This resulted in a detergent/ drug suspension $(5.0 \mathrm{mg} / \mathrm{mL})$, which was then sonicated and diluted with saline to final injection doses $(1.0 \mathrm{mg} / \mathrm{kg} \mathrm{WIN}-2 ; 0.08 \mathrm{mg} / \mathrm{kg}$ 
MK-801; $0.2 \mathrm{mg} / \mathrm{kg}$ scopolamine; $1.5 \mathrm{mg} / \mathrm{kg}$ AM-281; $1.0 \mathrm{mg} / \mathrm{kg}$ rivastigmine). The vehicle (Pluronic F68) was prepared in a similar manner, except the drug was omitted. All drug solutions were made fresh every day and administered in $1 \mathrm{~mL} / \mathrm{kg}$ body weight.

\section{Behavioral experiments}

All subjects in Experiment $1(\mathrm{n}=6)$ were administered (i.p.) with scopolamine $(0.2 \mathrm{mg} / \mathrm{kg})$ or rivastigmine $(1.0 \mathrm{mg} / \mathrm{kg})$, or scopolamine $(0.2 \mathrm{mg} / \mathrm{kg})+$ rivastigmine $(1.0 \mathrm{mg} / \mathrm{kg})$, or vehicle (Pluronic F68) according to a randomly assigned schedule on separate test days. Similarly, animals in Experiment 2a $(\mathrm{n}=6)$ were administered with WIN-2 $(1.0 \mathrm{mg} / \mathrm{kg})$, or WIN-2 $(1.0 \mathrm{mg} / \mathrm{kg})+$ rivastigmine $(1.0 \mathrm{mg} / \mathrm{kg})$, or WIN-2 $(1.0 \mathrm{mg} / \mathrm{kg})+$ scopolamine $(0.2$ $\mathrm{mg} / \mathrm{kg})$, or vehicle, and those in Experiment $4 \mathrm{a}(\mathrm{n}=6)$ were given MK-801 $(0.08 \mathrm{mg} / \mathrm{kg})$, or MK-801 $(0.08 \mathrm{mg} / \mathrm{kg})+\mathrm{WIN}-2(1.0 \mathrm{mg} / \mathrm{kg})$, or MK801 $(0.08 \mathrm{mg} / \mathrm{kg})+$ rivastigmine $(1.0$ $\mathrm{mg} / \mathrm{kg})$, or MK801 $(0.08 \mathrm{mg} / \mathrm{kg})+\mathrm{WIN}-2(1.0 \mathrm{mg} / \mathrm{kg})+$ rivastigmine $(1.0 \mathrm{mg} / \mathrm{kg})$, or vehicle, respectively. All injections were given approximately $15 \mathrm{~min}$ prior to DNMS testing.

\section{Behavioral apparatus}

The apparatus was similar to that used in other studies from this laboratory (Deadwyler et al. 1996; Hampson and Deadwyler 2000; Hampson et al. 2003), which consisted of a $43 \times 43 \times$ $50 \mathrm{~cm}$ Plexiglas behavioral testing chamber with two retractable levers (left and right) mounted on either side of a water trough on one wall, and a nosepoke device mounted in the center of the opposite wall. The entire apparatus was housed inside a commercially built sound attenuated cubicle (Industrial Acoustics Co.). The two retractable levers (Coulborn Instruments) were positioned $3.5 \mathrm{~cm}$ above the floor and separated $14.0 \mathrm{~cm}$ center-to-center. The nosepoking device consisted of an infrared photo detector and light-emitting diode spanning a $2.5 \times 1 \times 1 \mathrm{~cm}$ opening in a delrin housing and was mounted $4.0 \mathrm{~cm}$ above the chamber floor, centered on the wall opposite the levers. A cue light $(6 \mathrm{~V}, 10 \mathrm{~W})$ was positioned immediately above the nosepoke device, and a speaker mounted overhead provided 85-dB "white noise." Two $28 \mathrm{~V}$ incandescent house lights were mounted on the top of the chamber. Video monitoring and computer tracking of the animal at all times was provided by a Sanyo CCD black-and-white video camera mounted above the chamber. The entire apparatus was controlled by personal computers, which collected all behavioral data and stored it on magnetic disks.

\section{Behavioral training procedure}

The DNMS task and pretraining were identical to those described previously by Goonawardena and coworkers (2009), and comprised three main phases: sample, delay, and nonmatch. At the initiation of a trial, either the left or right lever was extended at 50\% overall probability, and the animal was required to press this lever to complete the sample phase of the task. The lever was immediately retracted, initiating the delay phase, signaled by the illumination of a cue light above the nosepoke device in the rear wall. The duration of the delay phase varied randomly on any given trial between 1 and $30 \mathrm{sec}$ (1-sec resolution) with equal likelihood for any duration. The subject was required to nosepoke in the photocell device on the opposite wall at least once during the delay before the interval was terminated. The last nosepoke after the delay interval turned off the cue light and simultaneously extended both levers in the front wall, signaling the onset of the nonmatch phase. The animal was required to press the lever not matching the one pressed during the sample phase to be rewarded with a droplet of water $(40 \mathrm{~mL})$ delivered to the trough between the two levers. This was recorded as a "correct" trial. At the termination of the nonmatch phase, the levers were retracted for a 10 -sec intertrial interval (ITI), at which time another trial was initiated by extension of a single lever. On "error" trials in which the inappropriate (i.e., "match") lever was pressed, an immediate 5-sec time-out (TO) period 
was initiated and the house lights turned off, leaving the chamber completely dark and both levers retracted with no water reward (see Fig. 1A). After the TO period, the lights were turned back on for an additional $5 \mathrm{sec}$ with no levers available (TO $+5 \mathrm{sec}=10 \mathrm{sec}$ ITI). A daily session consisted of 100 trials, and performance was recorded as percentage of correct responses. The average time required to train a naïve animal to criterion in the DNMS task with 1- to 30-sec delays was _3-4 wk. A final criterion of $90 \%$ correct responding on trials with delays of 1-5 sec was used for all animals (Deadwyler et al. 1996; Hampson and Deadwyler 2000). We did not observe errors of omission.

\section{Analysis of behavioral data}

Performance under the influence of each treatment in Experiments 1, 2a, and 4a was assessed using two primary measures: (1) mean percentage of correct trials per session and (2) mean percentage of correct trials at each delay interval (blocked for $5 \mathrm{sec}$ ). Statistical reliability was confirmed using one-way repeated-measures ANOVAs across all treatment groups followed by Bonferroni post-hoc tests comparing between groups of interest.

Additionally, two-way repeated-measures ANOVAs using drug treatment $\times$ delay interval as factors were employed followed by post-hoc (Bonferroni) analysis with probability values set to $\mathrm{p}<0.05$. Only terms for reliable differences are indicated in the text; all other comparisons were nonsignificant.

\section{Electrophysiological experiments}

Electrophysiological experiments consisted of Experiments 2b, 3, and $4 \mathrm{~b}$ in which the same hippocampal principal cells were isolated (see Surgery and Multi-neuron recording technique) and "tracked" across 20-min sessions following drug administration. Drugs were administered (i.p.) in the following order: Experiment 2b: vehicle (Pluronic F68), WIN-2 $(1.0 \mathrm{mg} / \mathrm{kg}$ ), rivastigmine (1.0 mg/kg); Experiment 3: vehicle (Pluronic F68), WIN-2 (1.0 $\mathrm{mg} / \mathrm{kg}$ ), AM-281 (1.5 mg/kg); and Experiment 4b: vehicle (Pluronic F68), MK-801 (0.08 $\mathrm{mg} / \mathrm{kg})$, WIN-2 $(1.0 \mathrm{mg} / \mathrm{kg})$, rivastigmine $(1.0 \mathrm{mg} / \mathrm{kg})$, respectively. All treatments were administered $15 \mathrm{~min}$ prior to the start of each respective recording session.

\section{Surgery}

Each pretrained animal was anesthetized with ketamine $(100 \mathrm{mg} / \mathrm{kg})$ and xylazine $(10 \mathrm{mg} /$ $\mathrm{kg}$ ) prior to restraining the head with ear bars in a stereotaxic frame (Stoelting). A craniotomy (5-mm diameter) was performed over the dorsal hippocampus. The center pair of array electrodes consisting of 16 stainless steel wires (diameter of each wire, $40 \mu \mathrm{m}$; Neurolinc Corp.) was positioned at coordinates $3.4 \mathrm{~mm}$ posterior and $3.0 \mathrm{~mm}$ lateral to bregma (Paxinos and Watson 1998) so that the longitudinal axis of the array was angled 308 to the midline, with posterior electrode sites angled outward. The array was driven in 25- to $100-\mu \mathrm{m}$ steps to a depth of $3.0-4.0 \mathrm{~mm}$ from the cortical surface for CA3 leads (eight long wires), with the CA1 leads (eight short wires) automatically positioned $1.2 \mathrm{~mm}$ higher along the longitudinal axis of the hippocampus. The array was designed such that the distance between two adjacent electrodes within a given row was $200 \mathrm{~mm}$ and between rows (long and short wires) was $400 \mu \mathrm{m}$ apart. Neural activity from the microwire electrodes were monitored throughout surgery to ensure placement in appropriate hippocampal cell layers, and the exposed cortex was kept moist with $0.9 \%$ sodium chloride. After array placement, the cranium was sealed with bone wax and dental cement. The animal was given an injection of Crysticillin (penicillin G, 300,000 U) to prevent infection soon after surgery and was allowed to recover for at least $1 \mathrm{wk}$ (Hampson and Deadwyler 2000; Goonawardena et al. 2009). The scalp wound was treated periodically with Neopredef (Pfizer) antibiotic powder. 


\section{Multi-neuron recording technique}

Following recovery from surgery, each animal was anesthetized under a constant flow of isoflurane $(1.5 \%) / \mathrm{O} 2(100 \%)$ mixture, and a cable (Plexon Inc.) was attached to the head stage. The activity of the principal neurons (extracellular action potentials, or "spikes")was isolated from each of the microwire electrodes placed in the CA3/CA1 hippocampal subfields based on time-amplitude window discrimination and computer-identified individual waveform characteristics using a multi-neuron acquisition processor (MAP; Plexon) digitizing neuronal activity at $40 \mathrm{KHz}$ (Hampson and Deadwyler 2000; Hampson et al. 2003). Only neurons with average firing rates of $0.25-6 \mathrm{~Hz}$ at rest were "tracked" following respective treatments.

\section{Recording parameters and analysis of neuronal data}

Single neuron spike trains were analyzed using Neuroexplorer software, and parameters computed for each selected principal cell across treatments included mean firing frequency (in hertz) and ISI. Moreover, "bursts" of spikes were characterized using the "surprise" method that identified sequences of at least three consecutive spikes with ISIs less than onehalf of the mean ISI over all spike occurrences. Bursts were identified by (1) finding the mean frequency and mean ISI for all spikes; (2) identifying sequences of three or more consecutive spikes with ISIs, in which all ISIs were less than one-half the mean ISI; (3) computing surprise $(\mathrm{S})$ such that $\mathrm{S}=-\log _{10}(\mathrm{P})$, where $\mathrm{P}$ is the probability that the same sequence of spikes could occur in a random Poisson distribution with the same mean frequency; and (4) maximizing S either by adding consecutive spikes to the end of the burst or by removing consecutive spikes from the beginning of the burst. Bursts with S-values $>10$ were then characterized according to mean number of bursts, mean burst duration, mean IBI, mean frequency within bursts, mean ISI within burst, and mean number of spikes per burst from 20-min spike trains following each respective treatment. Overall statistical significance was assessed using one-way repeated-measures ANOVAs followed by subsequent post-hoc (Bonferroni) tests with probability values set at $\mathrm{p}<0.05$. Only terms for reliable differences are indicated in the text; all other comparisons were nonsignificant.

\section{Acknowledgments}

We thank Drs. Sam A. Deadwyler and Bettina Platt for discussion and advice on earlier versions of this manuscript. This work was supported by National Institutes of Health (NIH) grant DA008549 to R.E.H. and G.R.

\section{References}

Acquas E, Pisanu A, Marrocu P, Di Chiara G. Cannabinoid CB(1) receptor agonists increase rat cortical and hippocampal acetylcholine release in vivo. Eur J Pharmacol. 2000; 401:179-185. [PubMed: 10924924]

Acquas E, Pisanu A, Marrocu P, Goldberg SR, Di Chiara G. $\Delta^{9}$-Tetrahydrocannabinol enhances cortical and hippocampal acetylcholine release in vivo: A microdialysis study. Eur J Pharmacol. 2001; 419:155-161. [PubMed: 11426837]

Beatty WW, Butters N, Janowsky DS. Patterns of memory failure after scopolamine treatment: Implications for cholinergic hypotheses of dementia. Behav Neural Biol. 1986; 45:196-211. [PubMed: 2938571]

Bejar C, Wang RH, Weinstock M. Effect of rivastigmine on scopolamine-induced memory impairment in rats. Eur J Pharmacol. 1999; 383:231-240. [PubMed: 10594314]

Braida D, Sala M. Cannabinoid-induced working memory impairment is reversed by a second generation cholinesterase inhibitor in rats. Neuroreport. 2000; 11:2025-2029. [PubMed: 10884065]

Carta G, Nava F, Gessa GL. Inhibition of hippocampal acetylcholine release after acute and repeated $\Delta^{9}$-tetrahydrocannabinol in rats. Brain Res. 1998; 809:1-4. [PubMed: 9795096] 
Deadwyler SA, Bunn T, Hampson RE. Hippocampal ensemble activity during spatial delayednonmatch-to-sample performance in rats. J Neurosci. 1996; 16:354-372. [PubMed: 8613802]

Deiana S, Harrington CR, Wischik CM, Riedel G. Methylthioninium chloride reverses cognitive deficits induced by scopolamine: Comparison with rivastigmine. Psychopharmacology. 2009; 202:53-65. [PubMed: 19005644]

Egashira N, Mishima K, Iwasaki K, Fujiwara M. Intracerebral microinjections of $\Delta^{9}$ tetrahydrocannabinol: Search for the impairment of spatial memory in the eight-arm radial maze in rats. Brain Res. 2002; 952:239-245. [PubMed: 12376185]

Fitz NF, Gibbs RB, Johnson DA. Selective lesion of septal cholinergic neurons in rats impairs acquisition of a delayed matching to position T-maze task by delaying the shift from a response to a place strategy. Brain Res Bull. 2008; 77:356-360. [PubMed: 18809473]

Gessa GL, Mascia MS, Casu MA, Carta G. Inhibition of hippocampal acetylcholine release by cannabinoids: Reversal by SR 141716A. Eur J Pharmacol. 1997; 327:R1-R2. [PubMed: 9185841]

Gessa GL, Casu MA, Carta G, Mascia MS. Cannabinoids decrease acetylcholine release in the medialprefrontal cortex and hippocampus, reversal by SR141716A. Eur J Pharmacol. 1998; 355:119124. [PubMed: 9760025]

Gifford AN, Ashby CR Jr. Electrically evoked acetylcholine release from hippocampal slices is inhibited by the cannabinoid receptor agonist, WIN 55212-2, and is potentiated by the cannabinoid antagonist, SR 141716A. J Pharmacol Exp Ther. 1996; 277:1431-1436. [PubMed: 8667207]

Gifford AN, Samiian L, Gatley SJ, Ashby CR Jr. Examination of the effect of the cannabinoid receptor agonist, CP 55,940, on electrically evoked transmitter release from rat brain slices. Eur J Pharmacol. 1997a; 324:187-192. [PubMed: 9145770]

Gifford AN, Tang Y, Gatley SJ, Volkow ND, Lan R, Makriyannis A. Effect of the cannabinoid receptor SPECT agent, AM 281, on hippocampal acetylcholine release from rat brain slices. Neurosci Lett. 1997b; 238:84-86. [PubMed: 9464661]

Gifford AN, Bruneus M, Gatley SJ, Volkow ND. Cannabinoid receptor-mediated inhibition of acetylcholine release from hippocampal and cortical synaptosomes. Br J Pharmacol. 2000; 131:645-650. [PubMed: 11015319]

Goonawardena AV, Robinson L, Riedel G, Hampson RE. Recruitment of hippocampal neurons to encode behavioral events in the rat: Alterations in cognitive demand and cannabinoid exposure. Hippocampus. 2009 (in press). doi: 10.1002/hipo.20706.

Goonawardena AV, Riedel G, Hampson RE. Cannabinoids alter spontaneous firing, bursting and cell synchrony of hippocampal principal cells. Hippocampus. 2010 (in press). doi:10.1002/hipo.20769.

Hampson RE, Deadwyler SA. Role of cannabinoid receptors in memory storage. Neurobiol Dis. 1998; 5:474-482. [PubMed: 9974179]

Hampson RE, Deadwyler SA. Cannabinoids, hippocampal function and memory. Life Sci. 1999; 65:715-723. [PubMed: 10462072]

Hampson RE, Deadwyler SA. Cannabinoids reveal the necessity of hippocampal neural encoding for short-term memory in rats. J Neurosci. 2000; 20:8932-8942. [PubMed: 11102504]

Hampson RE, Simeral JD, Kelly EJ, Deadwyler SA. Tolerance to the memory disruptive effects of cannabinoids involves adaptation by hippocampal neurons. Hippocampus. 2003; 13:543-556. [PubMed: 12921345]

Harkany T, Hartig W, Berghuis P, Dobszay MB, Zilberter Y, Edwards RH, Mackie K, Ernfors P. Complementary distribution of type 1 cannabinoid receptors and vesicular glutamate transporter 3 in basal forebrain suggests input-specific retrograde signalling by cholinergic neurons. Eur J Neurosci. 2003; 18:1979-1992. [PubMed: 14622230]

Harkany T, Dobszay MB, Cayetanot F, Hartig W, Siegemund T, Aujard F, Mackie K. Redistribution of $\mathrm{CB} 1$ cannabinoid receptors during evolution of cholinergic basal forebrain territories and their cortical projection areas: A comparison between the gray mouse lemur (Microcebus murinus, primates) and rat. Neuroscience. 2005; 135:595-609. [PubMed: 16129564]

Heyser CJ, Hampson RE, Deadwyler SA. Effects of $\Delta^{9}$-tetrahydrocannabinol on delayed match to sample performance in rats: Alterations in short-term memory associated with changes in task specific firing of hippocampal cells. J Pharmacol Exp Ther. 1993; 264:294-307. [PubMed: 8380864] 
Hironaka N, Ando K. Effects of cholinergic drugs on scopolamine-induced memory impairment in rhesus monkeys. Nihon Shinkei Seishin Yakurigaku Zasshi. 1996; 16:103-108. [PubMed: 8905798]

Kathmann M, Weber B, Schlicker E. Cannabinoid CB1 receptor-mediated inhibition of acetylcholine release in the brain of NMRI, CD-1 and C57BL/6J mice. Naunyn Schmiedebergs Arch Pharmacol. 2001a; 363:50-56. [PubMed: 11191836]

Kathmann M, Weber B, Zimmer A, Schlicker E. Enhanced acetylcholine release in the hippocampus of cannabinoid CB(1) receptor-deficient mice. Br J Pharmacol. 2001b; 132:1169-1173. [PubMed: 11250865]

Katona I, Sperlagh B, Sik A, Kafalvi A, Vizi ES, Mackie K, Freund TF. Presynaptically located CB1 cannabinoid receptors regulate GABA release from axon terminals of specific hippocampal interneurons. J Neurosci. 1999; 19:4544-4558. [PubMed: 10341254]

Katona I, Urban GM, Wallace M, Ledent C, Jung KM, Piomelli D, Mackie K, Freund TF. Molecular composition of the endocannabinoid system at glutamatergic synapses. J Neurosci. 2006; 26:5628-5637. [PubMed: 16723519]

Kawamura Y, Fukaya M, Maejima T, Yoshida T, Miura E, Watanabe M, Ohno-Shosaku T, Kano M. The CB1 cannabinoid receptor is the major cannabinoid receptor at excitatory presynaptic sites in the hippocampus and cerebellum. J Neurosci. 2006; 26:2991-3001. [PubMed: 16540577]

Lichtman AH, Martin BR. D9-Tetrahydrocannabinol impairs spatial memory through a cannabinoid receptor mechanism. Psychopharmacology. 1996; 126:125-131. [PubMed: 8856831]

Lichtman AH, Dimen KR, Martin BR. Systemic or intrahippocampal cannabinoid administration impairs spatial memory in rats. Psychopharmacology. 1995; 119:282-290. [PubMed: 7675962]

Mishima K, Egashira N, Matsumoto Y, Iwasaki K, Fujiwara M. Involvement of reduced acetylcholine release in $\Delta^{9}$-tetrahydrocannabinol-induced impairment of spatial memory in the eight-arm radial maze. Life Sci. 2002; 72:397-407. [PubMed: 12467880]

Monory K, Massa F, Egertova M, Eder M, Blaudzun H, Westenbroek R, Kelsch W, Jacob W, Marsch $\mathrm{R}$, Ekker M, et al. The endocannabinoid system controls key epileptogenic circuits in the hippocampus. Neuron. 2006; 51:455-466. [PubMed: 16908411]

Nava F, Carta G, Colombo G, Gessa GL. Effects of chronic $\Delta^{9}$-tetrahydrocannabinol treatment on hippocampal extracellular acetylcholine concentration and alternation performance in the T-maze. Neuropharmacology. 2001; 41:392-399. [PubMed: 11522331]

Paxinos, G.; Watson, C. The rat brain in stereotaxic coordinates. 4th ed. Academic Press; New York: 1998.

Riedel G, Davies SN. Cannabinoid function in learning, memory and plasticity. Handb Exp Pharmacol. 2005; 168:445-477. [PubMed: 16596784]

Riedel, G.; Platt, B. From messengers to molecules: Memories are made of these. Kluwer; New York: 2004.

Riedel G, Platt B, Micheau J. Glutamate receptor function in learning and memory. Behav Brain Res. 2003; 140:1-47. [PubMed: 12644276]

Robinson L, Riedel G. Cannabinoid function in spatial learning: An update. Curr Neuropharmacol. 2004; $2: 125-143$.

Robinson L, Goonawardena AV, Pertwee RG, Hampson RE, Riedel G. The synthetic cannabinoid HU210 induces spatial memory deficits and suppresses hippocampal firing rate in rats. $\mathrm{Br} \mathbf{J}$ Pharmacol. 2007; 151:688-700. [PubMed: 17502849]

Robinson L, Goonawardena AV, Pertwee RG, Hampson RE, Platt B, Riedel G. WIN55,212-2 induced deficits in spatial learning are mediated by cholinergic hypofunction. Behav Brain Res. 2010; 208:584-592. [PubMed: 20079375]

Sullivan JM. Mechanisms of cannabinoid-receptor-mediated inhibition of synaptic transmission in cultured hippocampal pyramidal neurons. J Neurophysiol. 1999; 8:1286-1294. [PubMed: 10482747]

Takahashi KA, Castillo PE. The CB1 cannabinoid receptor mediates glutamatergic synaptic suppression in the hippocampus. Neuroscience. 2006; 139:795-802. [PubMed: 16527424] 
Terranova JP, Storme JJ, Lafon N, Perio A, Rinaldi-Carmona M, Le Fur G, Soubrie P. Improvement of memory in rodents by the selective CB1 cannabinoid receptor antagonist, SR 141716. Psychopharmacology (Berl). 1996; 126:165-172. [PubMed: 8856836]

Thomas E, Snyder PJ, Pietrzak RH, Jackson CE, Bednar M, Maruff P. Specific impairments in visuospatial working and short-term memory following low-dose scopolamine challenge in healthy older adults. Neuropsychologia. 2008; 46:2476-2484. [PubMed: 18514746]

Tsou K, Mackie K, Sanudo-Pena MC, Walker JM. Cannabinoid CB1 receptors are localized primarily on cholecystokinin-containing GABAergic interneurons in the rat hippocampal formation. Neuroscience. 1999; 93:969-975. [PubMed: 10473261]

Tzavara ET, Wade M, Nomikos GG. Biphasic effects of cannabinoids on acetylcholine release in the hippocampus: Site and mechanism of action. J Neurosci. 2003; 23:9374-9384. [PubMed: 14561865]

Wang RH, Bejar C, Weinstock M. Gender differences in the effect of rivastigmineon brain cholinesterase activity and cognitive function in rats. Neuropharmacology. 2000; 39:497-506. [PubMed: 10698015] 


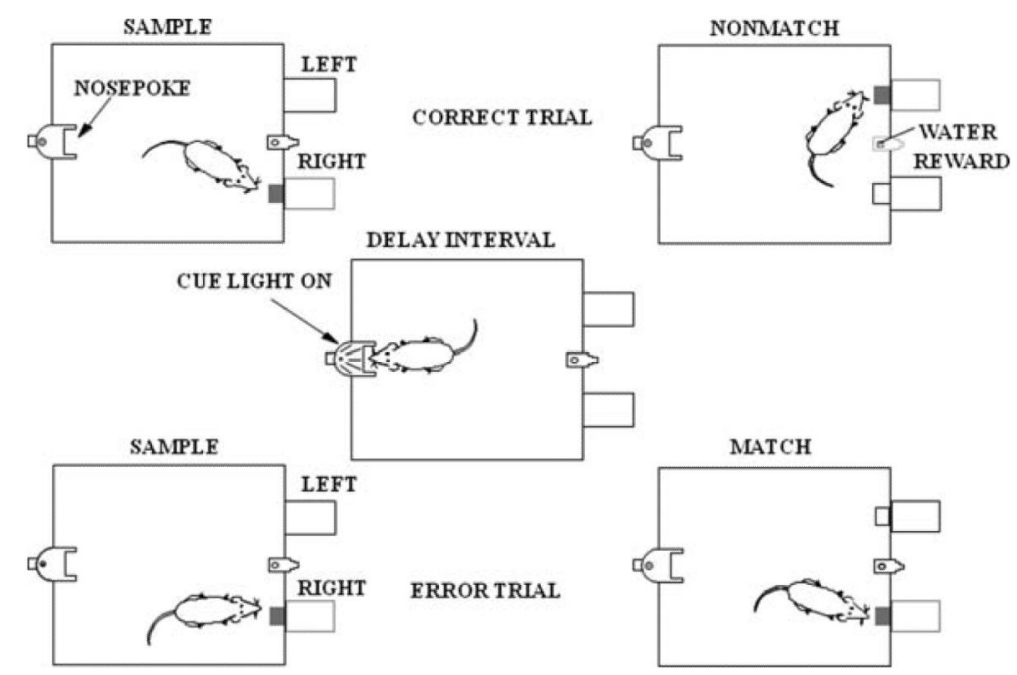

Figure 1.

The three main phases (i.e., sample, delay, and nonmatch) of the DNMS task and the difference between a "correct" and "error" trial. The subject is reinforced with a "water" reward only if it nonmatches the sample (correct trial) but not if it matches the sample (error trial). All animals were given 100 trials with delays ranging from 1-30 sec for each trial. 


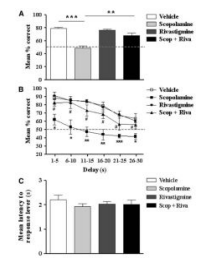

Figure 2.

Mean+SEMs of percentage of correct responses on overall DNMS performance (A) and delay-dependent DNMS performance (B) following the treatment of vehicle, scopolamine $(0.2 \mathrm{mg} / \mathrm{kg})$, rivastigmine $(1.0 \mathrm{mg} / \mathrm{kg})$, and scopolamine $(0.2 \mathrm{mg} / \mathrm{kg})+$ rivastigmine $(1.0 \mathrm{mg} /$ $\mathrm{kg})$, respectively. Scopolamine alone impaired overall DNMS performance $(* * * \mathrm{p}<0.001 ; \mathrm{A})$ across all delay intervals in comparison to vehicle $(* \mathrm{p}<0.05 ; * * \mathrm{p}<0.01 ; * * * \mathrm{p}<0.001 ; \mathrm{B})$. Rivastigmine and scopolamine together were able to reverse the scopolamine-induced deficits in DNMS performance across all delay intervals $(\# \mathrm{p}<0.05$; B). Rivastigmine alone failed to produce significant changes in DNMS performance. (C) Mean+SEMs of latency to move to response lever after the last nosepoke during DNMS performance following respective treatments. None of the treatments produced alterations in locomotor activity. The dotted lines indicate chance level $(50 \%)$ of performance. 


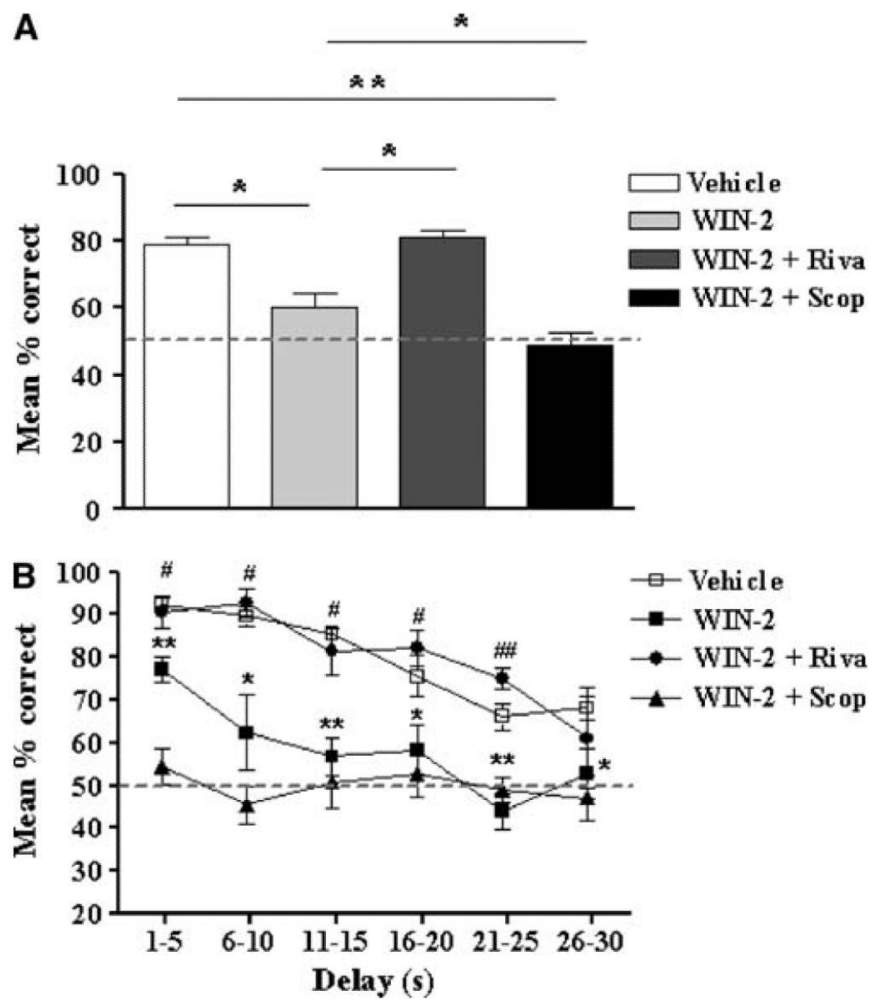

Figure 3.

Mean+SEMs of percentage of correct responses on overall DNMS performance (A) and delay-dependent DNMS performance (B) following the treatment of vehicle, WIN-2 (1.0 $\mathrm{mg} / \mathrm{kg})$, WIN-2 $(1.0 \mathrm{mg} / \mathrm{kg})+$ rivastigmine $(1.0 \mathrm{mg} / \mathrm{kg})$, and WIN-2 $(1.0 \mathrm{mg} / \mathrm{kg})+$ scopolamine $(0.2 \mathrm{mg} / \mathrm{kg})$, respectively. WIN-2 alone impaired overall DNMS performance $(* \mathrm{p}<0.05 ; \mathrm{A})$ across all delay intervals in comparison to vehicle $(* \mathrm{p}<0.05, * * \mathrm{p}<0.01 ; \mathrm{B})$, while administration of WIN-2 and scopolamine together further exacerbated the overall WIN-2-induced DNMS deficits (*p<0.05; A). Co-administration of WIN-2 and rivastigmine produced significantly better DNMS performance in comparison to WIN-2 alone across all delays except for intervals greater than $25 \mathrm{sec}(\# \mathrm{p}<0.05$; \#\#p<0.01; B). Note that no significant differences in DNMS performances were observed between WIN-2 + rivastigmine vs. vehicle treatments $(\mathrm{A}, \mathrm{B})$. The dotted lines indicate chance level $(50 \%)$ of performance. 

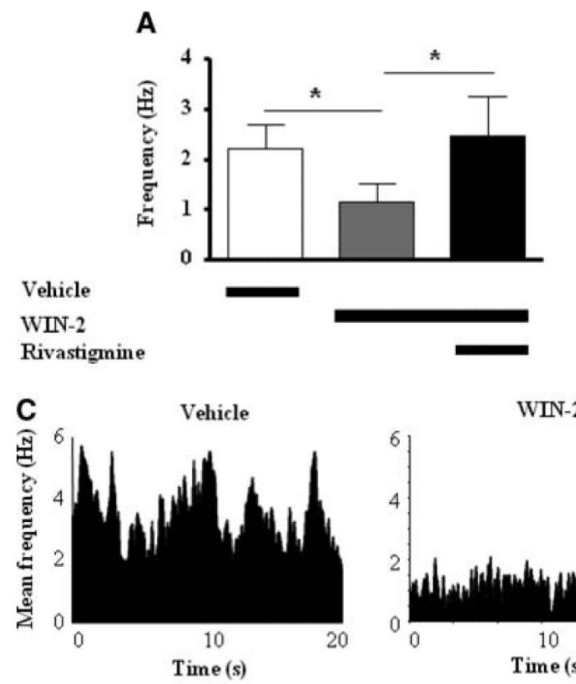

D

$$
\begin{aligned}
& \text { Raster 1 || ||| || ||| || | | || || | || } \\
& \text { Raster2 ||| || || || || || | || |||| || } \\
& \text { Raster3 |||| | ||| || ||| || ||| || } \\
& \text { Raster4 || || || ||| || ||| | }
\end{aligned}
$$

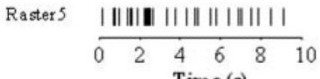
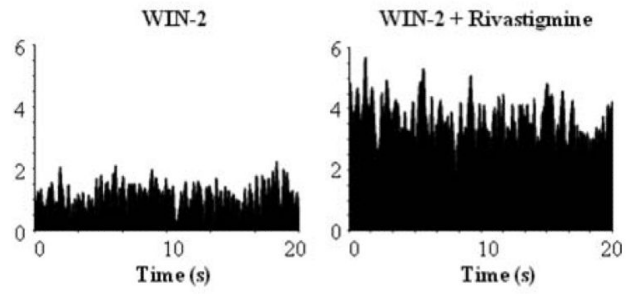

Figure 4.

Mean+SEMs of firing frequency (A) and interspike interval (B) recorded from preselected CA3/CA1 principal cells $(\mathrm{n}=24)$ following vehicle, WIN-2 $(1.0 \mathrm{mg} / \mathrm{kg})$, and rivastigmine $(1.0 \mathrm{mg} / \mathrm{kg})$ treatments, respectively. WIN-2-induced reductions in firing frequency were reversed by rivastigmine treatment. (C) Activity of a single CA1 principal cell represented by its mean firing frequency (bin size $=3 \mathrm{sec}$ ) across 20-min recording sessions following respective treatments. (D) Groups of raster plots (each lasting $10 \mathrm{sec}$ ) obtained randomly from the same cell represented in $\mathrm{C}$ following respective treatments. ${ }^{*} \mathrm{p}<0.05$. 
A

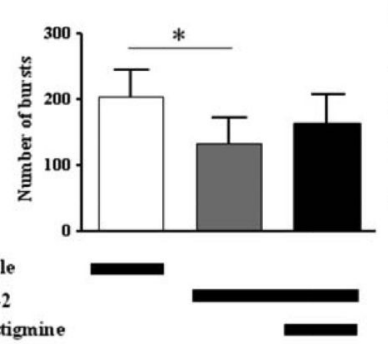

D

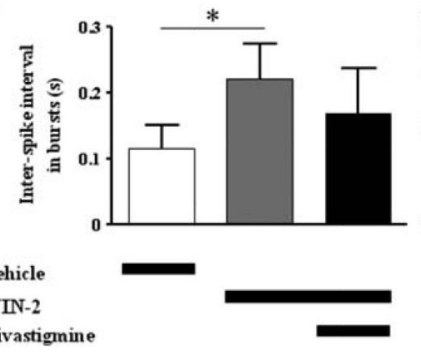

B
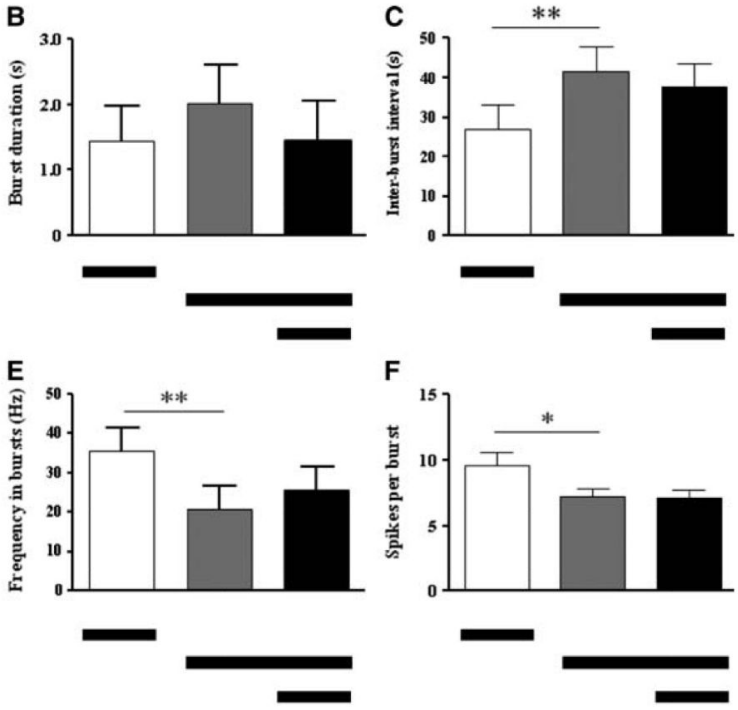

$\mathbf{F}$

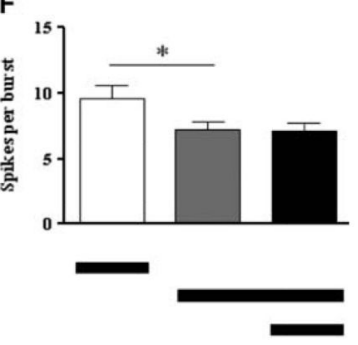

Figure 5.

Overall burst analysis of recordings from hippocampal principal cells. Means+SEM of number of bursts (A), burst duration (B), interburst interval (C), interspike interval in bursts (D), frequency in bursts (E), and spikes per burst (F) across 20-min electrophysiological recordings calculated from neurons $(n=24)$ located in CA3/CA1 subfields following vehicle, WIN-2 $(1.0 \mathrm{mg} / \mathrm{kg})$, and rivastigmine $(1.0 \mathrm{mg} / \mathrm{kg})$ treatments. WIN-2 induced strong reductions in bursting as evidenced by changes in most burst characteristics. Subsequent treatment of rivastigmine failed to reverse these WIN-2-induced changes in bursts. $* \mathrm{p}<0.05 ; * * \mathrm{p}<0.01$. 


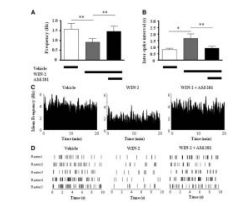

Figure 6.

Mean+SEMs of firing frequency (A) and interspike interval (B) recorded from preselected CA3/CA1 principal cells $(n=12)$ following vehicle, WIN-2 $(1.0 \mathrm{mg} / \mathrm{kg})$, and AM-281 $(1.5$ $\mathrm{mg} / \mathrm{kg}$ ) treatments, respectively. WIN-2-induced suppression in firing frequency was reversed by AM-281 treatment. (C) Activity of a single CA1 principal cell represented by its mean firing frequency (bin size $=3 \mathrm{sec}$ ) across 20 -min recording sessions following respective treatments. (D) Groups of raster plots (each lasting $10 \mathrm{sec}$ ) obtained randomly from the same cell represented in $\mathrm{C}$ following respective treatments. ${ }^{*} \mathrm{p}<0.05 ; * * \mathrm{p}<0.01$. 


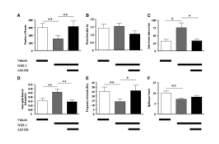

Figure 7.

Overall burst analysis of recordings from hippocampal principal cells. Mean+SEM of number of bursts (A), burst duration (B), interburst interval (C), interspike interval in bursts (D), frequency in bursts (E), and spikes per burst (F) across 20-min electrophysiological recordings calculated from neurons $(n=12)$ located in CA3/CA1 subfields following vehicle, WIN-2 (1.0 mg/kg), and AM-281 (1.5 mg/kg) treatments, respectively. AM-281 reversed the WIN-2-induced reductions in bursting activity. ${ }^{*} \mathrm{p}<0.05 ;{ }^{*} \mathrm{p}<0.01$. 

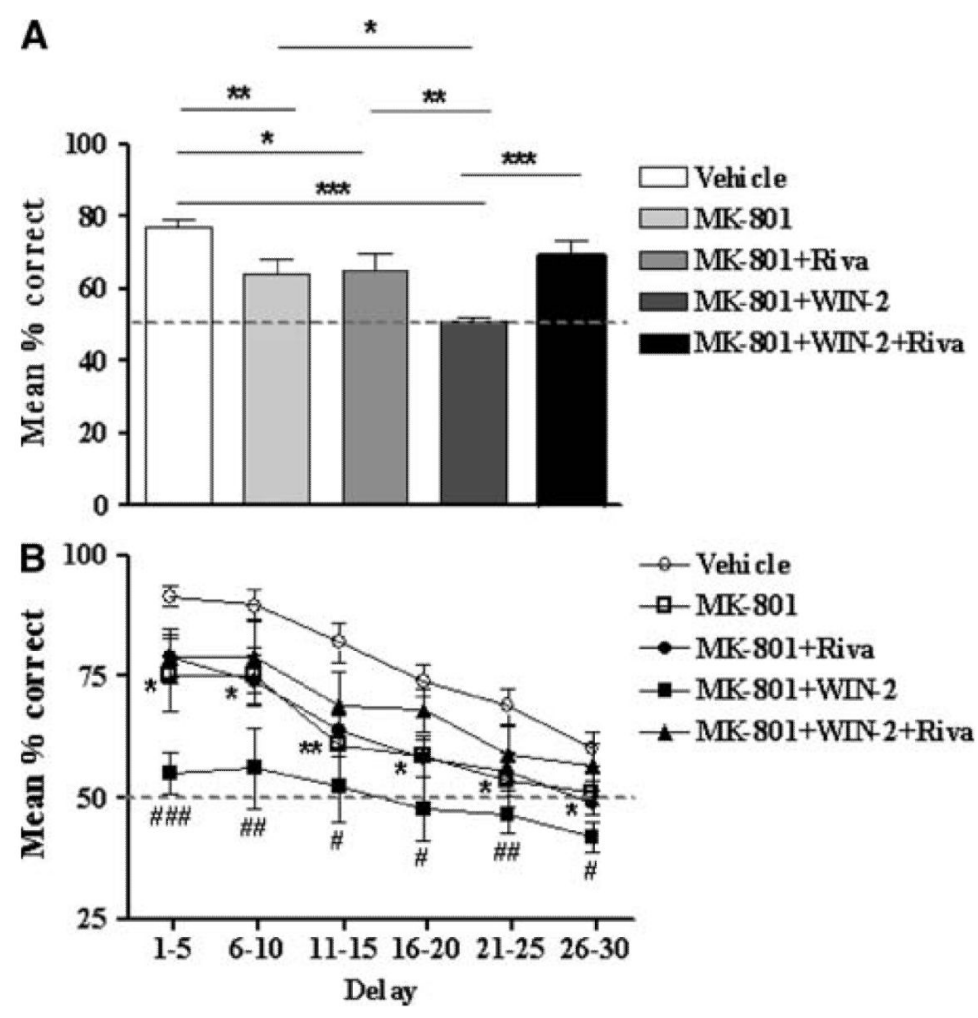

Figure 8.

Mean+SEMs of percentage of correct responses on overall DNMS performance (A) and delay-dependent DNMS performance (B) following the treatment of vehicle, MK-801 (0.08 $\mathrm{mg} / \mathrm{kg}), \mathrm{MK}-801(0.08 \mathrm{mg} / \mathrm{kg})+$ rivastigmine $(1.0 \mathrm{mg} / \mathrm{kg}), \mathrm{MK}-801(0.08 \mathrm{mg} / \mathrm{kg})+\mathrm{WIN}-2$ $(1.0 \mathrm{mg} / \mathrm{kg})$, and MK-801 $(0.08 \mathrm{mg} / \mathrm{kg})+\mathrm{WIN}-2(1.0 \mathrm{mg} / \mathrm{kg})+$ rivastigmine $(1.0 \mathrm{mg} / \mathrm{kg})$, respectively. MK-801 alone impaired overall DNMS performance in comparison to vehicle $(* * \mathrm{p}<0.01 ; \mathrm{A})$. This deficit was eminent across all delay intervals $(* \mathrm{p}<0.05, * * \mathrm{p}<0.01 ; \mathrm{B})$. MK801 + WIN-2 further exacerbated the overall DNMS deficit induced by MK-801 $(* \mathrm{p}<0.05 ; \mathrm{A})$ across all delay intervals $(\# \mathrm{p}<0.05, \# \# \mathrm{p}<0.01, \# \# \# \mathrm{p}<0.001 ; \mathrm{B})$. The DNMS performance following treatments of MK-801 + rivastigmine and MK-801 + WIN-2 + rivastigmine was not significantly different from MK-801 alone. The dotted line indicates the chance level $(50 \%)$ of performance. 

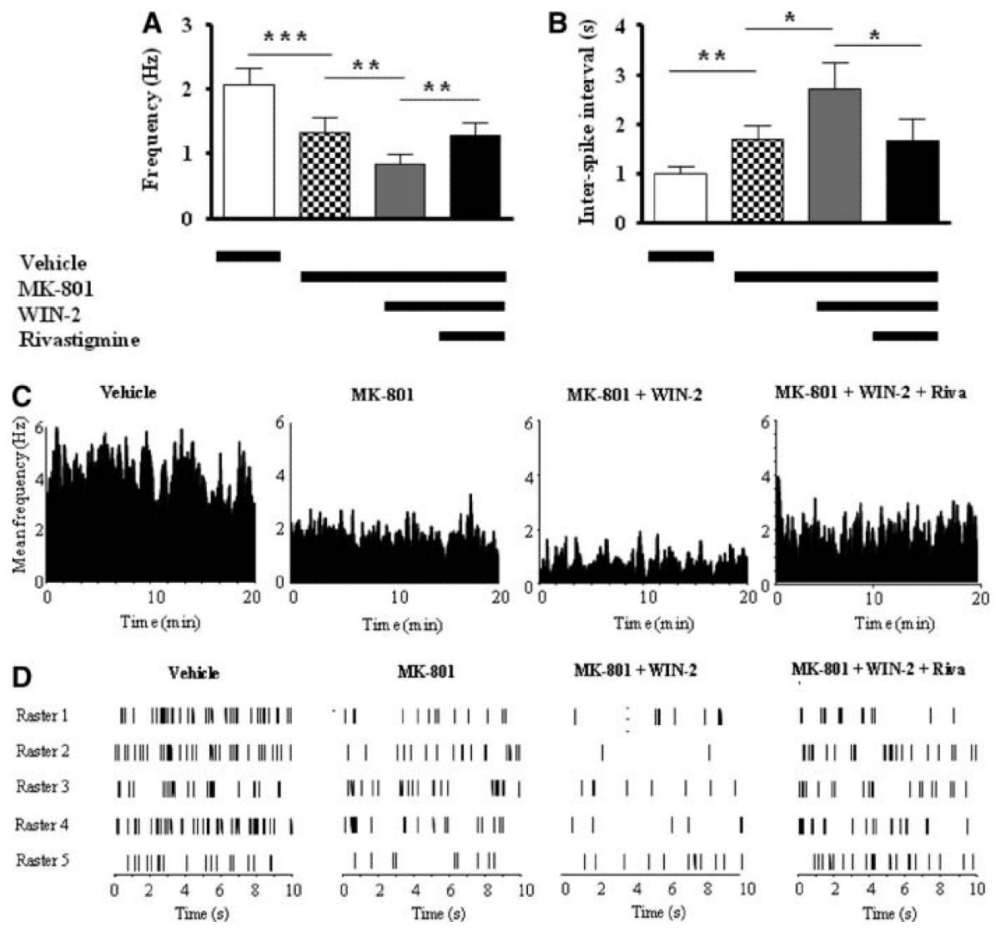

MK-801

MK-801 + WIN-2

MK-801 + WIN-2 + Riva

Figure 9.

Mean+SEMs of firing frequency (A) and interspike intervals (B) recorded from preselected CA3/CA1 principal cells $(\mathrm{n}=30)$ following vehicle, MK-801 $(0.08 \mathrm{mg} / \mathrm{kg})$, WIN-2 $(1.0 \mathrm{mg} /$ $\mathrm{kg})$, and rivastigmine $(1.0 \mathrm{mg} / \mathrm{kg})$ treatments, respectively. MK-801-induced suppression in baseline firing frequency was further exacerbated by WIN-2. Subsequent treatment of rivastigmine was only able to reverse the WIN-2-induced changes in overall firing frequency. (C) Activity of a single CA1 principal cell represented by its mean firing frequency (bin size $=3 \mathrm{sec}$ ) across 20-min recording sessions following respective treatments. (D) Groups of raster plots (each lasting $10 \mathrm{sec}$ ) obtained randomly from the same cell represented in $\mathrm{C}$ following respective treatments. ${ }^{*} \mathrm{p}<0.05 ;{ }^{*} \mathrm{p}<0.01 ; * * * \mathrm{p}<0.001$. 